\title{
Promovendo a motivação do aluno: contribuições da teoria da atribuição de causalidade
}

\author{
Promoting the motivation of the student: contributions of the \\ theory of attribution of causality
}

As atuais teorias cognitivas da motivação priorizam o estudo das crenças, valores e emoções do indivíduo, por considerarem que essas são mediadoras do comportamento e exercem forte influência no processo motivacional. Dentre o conjunto de crenças relacionadas à aprendizagem e ao desempenho dos alunos, destaca-se o papel das atribuições de causalidade, que dizem respeito às crenças pessoais sobre as causas responsáveis pelas experiências de sucesso ou fracasso escolar (Weiner, 1985).

De acordo com a Teoria da Atribuição de Causalidade (Weiner, 1985), as atribuições mais freqüentemente utilizadas pelos alunos em situações de sucesso ou fracasso escolar são a inteligência, o esforço, a dificuldade da tarefa e a sorte. Como são inúmeras as causas concebíveis para o sucesso ou fracasso escolar, Weiner (1985) sugeriu um esquema de classificação das atribuições, definindo a existência de três dimensões: a internalidade (causas internas ou externas ao sujeito), a estabilidade (causas estáveis ou instáveis) e a controlabilidade (causas controláveis ou incontroláveis pelo sujeito).

As atribuições, interpretadas pelos alunos nas dimensões da causalidade, influenciam as expectativas, as emoções, a motivação para a aprendizagem e o desempenho acadêmico. Em situações de fracasso, a estabilidade da causa pode resultar na redução da expectativa de sucesso futuro e a níveis mais altos de ansiedade, o inverso ocorrendo quando a causa é tida como instável. Causas estáveis e internas ao fracasso geram sentimentos de incompetência e vergonha e, em longo prazo, podem levar à depressão e ao desamparo. Causas controláveis de fracasso suscitam sentimentos de culpa, ao passo que as incontroláveis resultam em vergonha. Quando se trata de sucesso, as causas internas e estáveis geram sentimentos de orgulho e competência, como também se associam a baixos níveis de ansiedade (Martini \& Boruchovitch, 2004).

De acordo com Boruchovitch e Martini (1997), as atribuições de esforço são, geralmente, mais construtivas para a aprendizagem. Diferentemente da inteligência, o esforço é predominantemente concebido como uma causa interna e controlável. Nesse sentido, um aluno que atribui o fracasso vivido à falta de esforço pode ter a crença de que mais esforço o levará ao sucesso no futuro. Porém, se este aluno interpreta que fracassou por não ter capacidade, uma causa interna e estável, não vai querer se esforçar. Em situações de sucesso o esforço também é desejável, pois leva ao reconhecimento de que o aluno é capaz, mas que a capacidade sozinha não basta.

No entanto, a ênfase inadequada sobre o esforço ou a falta de esforço como causa responsável pelo sucesso ou fracasso escolar, pode trazer algumas conseqüências negativas ao aluno. A percepção de competência do aluno em relação à tarefa pode ser altamente prejudicada, caso ele acredite ter se esforçado ao máximo, mas receba do professor um feedback de falta de esforço para o fracasso. É fundamental, portanto, que os professores conheçam as atribuições de causalidade de seus alunos, as utilizem quando pertinentes às atribuições de esforço, mas sempre associadas ao uso adequado de estratégias de aprendizagem (Martini \& Boruchovitch, 2004).

O conhecimento sobre as atribuições de causalidade dos alunos favorece a implementação de programas de retreinamento, em que são alteradas as causas incompatíveis com a motivação para aprendizagem e com o bom desempenho escolar. De modo geral, as causas do fracasso de externas, estáveis e não controláveis, são modificadas para internas, instáveis e controláveis. Além disso, os alunos são auxiliados a perceberem a possibilidade de terem utilizado estratégias de aprendizagem inapropriadas, muito embora tenham se esforçado (Boruchovitch \& Martini, 1997).

$\mathrm{Na}$ realidade brasileira, um recente trabalho desenvolvido por Marques, De Rose, Del'Arco e Martini (2006), com crianças de oito anos de idade, com dificuldades de aprendizagem em Português e, ainda, baixo autoconceito acadêmico nessa área, mostra os efeitos positivos de uma intervenção baseada no retreinamento atribucional. A intervenção consistiu, basicamente, da utilização do feedback de desempenho focalizado internamente (ex. você se saiu muito bem nesta atividade de leitura) e do feedback atribucional (atribuições de capacidade e esforço para o sucesso e de falta de esforço para fracasso, juntamente com relatos de capacidade e uso de estratégias adequadas), ambos contingentes ao desempenho dos alunos em atividades planejadas pelas pesquisadoras em leitura e escrita. Constatou-se um fortalecimento entre os alunos do uso de atribuições para o sucesso ao próprio esforço e capacidade e da atribuição de falta de esforço para o fracasso, bem como uma melhora substancial nas habilidades leitura e escrita e no autoconceito acadêmico destes alunos.

As atribuições de causalidade são, portanto, passíveis de mudança e o conhecimento sobre elas pode oferecer importantes subsídios para a construção de um contexto simbólico mais favorável ao sucesso escolar. Vale ressaltar que, quanto mais cedo uma crença é aprendida maior será a dificuldade para alterá-la, o que justifica o investimento em se conhecer e trabalhar sobre as crenças dos alunos desde o início do processo escolar (Martini \& Boruchovitch, 2004).

Articulado ao trabalho sobre as crenças atribucionais dos alunos, a literatura da área (Martini \& Boruchovitch, 2004) tem sugerido uma série de ações docentes que se associam sistematicamente à promoção da motivação e do bom desempenho acadêmico dos alunos, dentre elas 
destaca-se: (a) o oferecimento de apoio, incentivo e orientação aos alunos; (b) a promoção de ações educacionais que visem ao aprimoramento pessoal do aluno e ao domínio da tarefa, em um ambiente de cooperação; (c) a elaboração de atividades de aprendizagem com nível adequado de complexidade, interessantes e desafiantes para os alunos (d) 0 desenvolvimento de avaliações que também promovam oportunidades de participação, aprendizagem e melhora do desempenho dos alunos e (e) o oferecimento de feedbacks positivos sobre a competência e a auto-eficácia dos alunos nas tarefas, incentivando relativamente 0 esforço e o uso adequado de estratégias de aprendizagem.

Sabe-se que problemas motivacionais podem comprometer seriamente a aprendizagem dos alunos, esta, por sua vez, representa um fator central para o desenvolvimento pessoal e acadêmico dos mesmos (Martini \& Boruchovitch, 2004). Espera-se que esta pequena introdução à Teoria da Atribuição de Causalidade possa motivar professores e educadores a buscarem estratégias de superação dos problemas motivacionais dos seus alunos, por meio da construção de crenças educacionais positivas e de um ambiente de sala de aula onde se evidencie o prazer de aprender e de ensinar.

\section{Referências}

Boruchovitch, E., \& Martini, M. L. (1997). As atribuições de causalidade para o sucesso e o fracasso escolar e a motivação para a aprendizagem de crianças brasileiras. Arquivos Brasileiros de Psicologia, 49(3), 59-71.

Marques, J., De Rose, T., Del'Arco, L., \& Martini, M. L. (2006). Intervenção para a promoção do autoconceito: combinando feedback focalizado internamente e feedback atribucional em situação de tutoria de leitura. Em Resumos de comunicações científicas, VIII Congresso Nacional de Psicologia Escolar e Educacional, 2006, São João del Rei. São João Del Rei: Associação Brasileira de Psicologia Escolar e Educacional.

Martini, M. L., \& Boruchovitch, E. (2004). A teoria da atribuição de causalidade: Contribuições para a formação e atuação de educadores. Campinas: Alínea.

Weiner, B. (1985). An attributional theory of achivement motivation and emotion. Psycological Rewiew, 92(4), 548-573.

\section{Sobre a autora:}

Mirella Lopez Martini Fernandes Paiva (mirellapaiva@gmail.com) - psicóloga pela Pontifícia Universidade Católica de Campinas, Mestre em Educação (Psicologia Educacional) pela UNICAMP e Doutora em Ciências (Psicologia) pela Faculdade de Filosofia, Ciências e Letras de Ribeirão Preto-USP. É membro do grupo de pesquisa Relações Interpessoais e Habilidades Sociais e do Núcleo de Estudo de Motivação Acadêmica da Universidade Federal de São Carlos, São Paulo/BR.

Endereço para correspondência: Rua XV de Novembro, 1168 -

CEP: 13561-206 - São Carlos/SP - Brasil.

Página Web: http://www.rihs.ufscar.br 